\title{
Motivation in foreign language learning: a look at type of school environment as a contextual variable
}

\author{
Višnja Pavičić Takač \\ Faculty of Humanities and Social Sciences, Osijek \\ Nives Berka
}

\begin{abstract}
Impelled by the observation that motivation might be one of the most important factors within the affective domain influencing foreign language learning (FLL), the field of second language acquisition (SLA) has seen an intense worldwide interest in empirical research in motivational issues. The studies have been rooted in different theories and methodologies, (most notably those advanced by Gardner and Dörnyei and their respective associates) that have given precedence to a number of variables assumed to play an important role in understanding the phenomenon of FLL motivation. The present study is set between the macroperspective of the social-psychological period-by giving a general view of second language motivation-and the situation-specific period-by taking into consideration the immediate learning context. It focuses on exploring the nature of FLL motivation in Croatia at secondary education level where FLL is part of core curriculum. In particular, it explores the role of one specific contextual variable that has been largely ignored in SLA motivational research, i.e. type of school environment, and its interaction with gender and success in FLL.
\end{abstract}

Key words: motivation; grammar school; vocational school; Croatia; EFL.

\section{Introduction}

Motivation has often been underscored as one of the most important psychological factors that enters multifaceted interactions with other affective, cognitive and contextual factors in the process of second language acquisition (SLA) ${ }^{1}$. Second language (L2) motivation has been an attractive research topic for a number of

\footnotetext{
1 In this paper, second language acquisition refers both to second and foreign language learning and acquisition.
} 
decades because it is perceived as a phenomenon that provides the initial impetus for L2 learning which turns into a driving force exerted, albeit to a varying extent, throughout the whole learning process.

In the global world we live in, the English language is present in almost every domain of human life and knowledge of English has become a necessity, not a luxury. As a consequence, learning English as a foreign language (EFL) has become an important part of general and professional education. The question how these trends affect EFL learners' motivation, i.e. the drive that pushes them and makes them interested in language learning is at the centre of the present study. In particular, in this paper we take a situative perspective by exploring the differences between learners situated in two different contexts, i.e. types of school: vocational and general secondary schools in Croatian socio-educational context where foreign language is taught at all levels of education.

After a brief review of major L2 motivational theories, selected related issues and relevant research findings in Sections 2 and 3, we report on the study carried out with the aim to better understand types and intensity of motivation of grammar and vocational secondary school EFL learners' in Section 4. In Section 5 the most important conclusions of this study are brought together, and implications and recommendations for future research are offered.

\section{Motivational theories in foreign and second language learning}

The view that human beings are essentially emotional creatures whose intellectual actions are governed by emotions has generated a lot of interest in the exploration of the affective domain and its role in SLA. A plethora of studies conducted over the last 30 or so years (for reviews see Gardner, 1985; Mihaljević Djigunović, 1998; Reid, 1999; Robinson, 2002; Ehrman et al., 2003; Dörnyei, 2005; Gregersen \& MacIntyre, 2014) have confirmed that success or failure in language learning cannot be attributed only to cognitive factors, but that affective factors - as prerequisites for cognitive learning - can contribute just as much, if not more (Arnold, 2011). Among these, motivation has held pride of place because, as one of the most influential researchers on the subject put it, "all the other factors involved in SLA presuppose motivation to some extent" (Dörnyei, 2005:65).

It is commonly agreed that motivation is complex to define. In fact Dörnyei (2001a:7) calls it "a real mystery" for which numerous studies could not provide a universal definition. Although it seems that we all intuitively know what motivation is, its exact nature and definition escapes any single theory. This can, first and foremost, be attributed to the innate complexity of human motives, i.e. humans' intentions, decisions and actions, which has forced researchers to focus on select issues thus failing to capture the multi-tier nature of motivation. However, all theories of motivation seek to answer the questions why a person chooses to engage 
in action and what makes him or her invest effort and persist (cf. Dörnyei \& Skehan, 2003:614).

SLA motivational theories historically fall into the following categories: the social psychological period (1959-1990), the cognitive situated period (during 1990s), the process-oriented period (the turn of the century), and the most recent sociodynamic period. In what follows, we will briefly outline the key features of each period $^{2}$.

The first period, the social psychological period, is mainly, although not only ${ }^{3}$, characterised by the work of Wallace Lambert, Robert Gardner and other social psychologists in Canada whose work has drummed up an extreme interest for motivation and other affective factors in SLA. The creation of the socio-educational model, the concept of integrative motive, and the Attitude/Motivation Test Battery (AMTB) are the contributions to the field that can scarcely be over-estimated.

The socio-educational model (Gardner, 1985; Gardner \& MacIntyre, 1993; Gardner, 2001; 2007) has dominated the field for over 40 years. Its appeal lies in the fact that it takes into consideration individual differences (both cognitive and affective) in language learning within the cultural context. Gardner and his followers view L2s as mediating factors between different communities. For them, language learning is socially rooted, and in order to master a L2, individuals need to develop a L2 identity. They agreed that "the learner's ethnocentric tendencies, his attitudes toward the other group, and his orientation toward language learning" (Lambert, 1972:291) have a significant mark on his motivation to learn and in the end, on the language learning achievement itself. In other words, for Gardner and Lambert (1972), learner's motivation is determined by two factors: his attitudes and readiness to identify and his orientation to the whole process of L2 learning. Thus, their conceptualisation of motivation encompasses four components: a goal, desire to achieve a goal, effort or intensity, and positive attitudes (Gardner, 1985:10). Truly motivated individuals display all components, whereas each component by itself is of little worth. In sum, language learning involves more than linguistic phenomena, it takes into account social context and interest in particular

2 For detailed overviews of L2 motivation research representing different perspectives see e.g. Dörnyei, 1998, 2001a, 2001b, 2005; MacIntyre, 2002; Cohen \& Dörnyei, 2002; Dörnyei \& Skehan, 2003; Dörnyei \& Ushioda, 2011; Dörnyei et al., 2015.

${ }^{3}$ A considerable contribution to research focusing on social psychological aspects of motivation has been made by Clément and his colleagues (cf. Clément \& Noels, 1992; Clément et al, 2001). Clément's social context model (Clément et al, 2003) proposes that cultural context (contact with the L2 community) leads to variations in L2 confidence. The model is primarily focused on the linguistic self-confidence as a socially defined construct and the most important attitudinal factor. From Clement's point of view, frequent contacts with L2 community members increase motivation for learning the other language and influence future decisions concerning intercultural communication and identification with the L2 members. 
culture which means that individuals' effort, desire and attitudes toward L2 community influence their success in language learning.

The key tenets of Gardner's motivational theory are the two major constructs: integrative and instrumental orientation. The first orientation concerns "motivation to learn a second language because of the positive feelings toward the community that speaks that language" (Gardner, 1985:82-3). Instrumental orientation reflects "the practical value and advantages of learning a new language" (Gardner and Lambert, 1972:132) and is often connected with some sort of pragmatic gain (e.g. better job or higher salary). The integrative motive, the most elaborate dimension of Gardner's theory, consists of three variables: integrativeness, attitudes towards the learning situation and motivation. Integrativeness "reflects genuine interest in learning the second language in order to come closer to the other language community" (Gardner, 2001:5). It is conceptualised as openness and respect for other community which can, in extreme cases, manifest as a complete identification with the group members. The second variable, attitudes towards the learning situation, comprises attitudes "toward any aspect of the situation in which the language is learned" (Gardner, 2001:5), such as the school context and attitudes directed toward the teacher, the classmates and the course. He also argues that it is natural that some learning situations in some individuals evoke more positive attitudes than in others. The last variable, motivation, as has already been stated, is comprised of three elements: effort, desire and attitudes towards learning the language.

Although Gardner's socio-educational model has been widely accepted, it has raised a lot of controversy and criticism mostly addressed at its conceptual definitions, terminological confusion and even some logical contradiction ${ }^{4}$ which have led to misinterpretations of Gardner's theory as being the sum of the two motivational orientations (cf. Crookes \& Schmidt, 1991; Oxford \& Shearin, 1994; Dörnyei, 1994, 2005; Dörnyei \& Ushioda, 2011).

The AMTB (Gardner, 1985) is a multicomponential instrument designed to measure a number of dimensions conceptualised in the socio-educational model. The three scales that measure integrativeness are attitudes towards the target language group, interest in foreign languages, and integrative orientation. Motivational intensity (the amount of effort invested in learning the language), attitudes toward learning the target language and the desire to learn the target language are the scales that measure motivation. Attitudes toward the teacher and attitudes toward the course are the two scales measuring the concept of attitudes toward the learning situation, i.e. a person's reactions to the immediate learning context. The

\footnotetext{
${ }^{4}$ Dörnyei (2005) has identified two sources of this misinterpretation. First is the term integrative which appears in 'integrative orientation', 'integrativeness', and 'integrative motive/motivation' without a clear disambiguation. The second is the term 'motivation' that can be found as a subcomponent of the overall construct of 'Integrative Motivation'.
} 
instrument also includes scales to measure L2 class anxiety and L2 use anxiety as typical representatives of language anxiety, i.e. learner's reactions in which they are asked to speak the target language, parental encouragement, and instrumental orientation. Even though the AMTB gained a lot of criticism (cf. Dörnyei, 2005) it has been considered a useful instrument that has been used and adapted for research in many learning contexts, including Croatia, where Mihaljević Djigunović (1996, 1997; 1998) carried out a number of studies focusing on types and intensity of EFL motivation in the Croatian socio-cultural context where FLL has for many decades now been mandatory at all levels of education and where English is primarily used for international communication. Starting from Gardner's AMTB, Mihaljević Djigunović $(1997,1998)$ designed a questionnaire for measuring types and intensity of motivation in a FLL context. In contrast to Gardner \& Lambert (1972), three types of motivation were found. Affective motivation refers to learners' wish to learn English because of specific aesthetic or emotional reasons (e.g. they like the language). Pragmatic-communicative motivation incorporates the instrumental and professional value learners attach to the knowledge and the status of English as a language of international communication. The last one, integrative motivation reflects learners' wish to be integrated into an English-speaking linguistic and cultural community. Furthermore, two sets of demotivators were revealed: one concerning the teaching setting and the other learning difficulties. In the Croatian context, pragmatic-communicative motivation seems to play a key role in EFL learning success (cf. Mihaljević, 1998).

Even when the new theories started to emerge, the influence of Gardner's theory did not wane: it was the starting point for the majority of all subsequent conceptualisations of motivation in SLA that sought to expand, not eliminate the socioeducational model. Thus, advances in cognitive theories in educational psychology led to the birth of a new period in L2 motivation research which was labelled cognitive-situated period. The focus shifted to the exploration of specific cognitive as well as situation-specific motives, such as immediate classroom environment and its potential impact on learners' motivation. This required expanding the existing theoretical framework to accommodate additional variables from mainstream motivational theories. These new L2 motivation models drew on the constructs put forward by, among others, attribution theory, self-determination theory, and task motivation. The premise was that a crucial aspect of motivation is how one thinks about one's abilities, possibilities, limitations, past performances, and how one thinks about many other aspects of the task to achieve or goals to attain.

Attribution theory (Weiner, 1985, as cited in Mihaljević Djigunović, 1998; Julkunen, 1989; Dörnyei, 1990; Ushioda, 1998) distinguishes the following dimensions of attributions: causal (external or internal), stability and personal control. Additional possible causes of success or failure are ability, task difficulty, effort and luck. According to Pintrich (2003), the attribution theory proposes that learner's attributions for success or failure influence or have consequences on future 
expectances. In the classroom context it means that learner's beliefs about achievement or mastering the material will influence actual studying. For example, learners who believe that particular task is hard to complete will not put as much actual effort in achieving it as those who believe the opposite.

The self-determination theory (SDT) proposed by Deci \& Ryan (1985), distinguishes two basic types of motivation: intrinsic, as doing something because it is interesting, and extrinsic, as having an instrumental value. They define selfdetermination as "a quality of human functioning that involves the experience of choice" (Deci \& Ryan, 1985:38) that is fundamental to intrinsic motivation. The importance of these concepts for L2 motivation has been recognised by SLA researchers, most notably Noels and her associates (Noels et al, 1999; 2000; 2001; Noels, 2009).

The focus on situation-specific aspects opened up another new path of enquiry: task-related motivation (cf. Julkunen, 2001; Dörnyei, 2002). Julkunen (2001) explored situation-specific motivation (i.e. i.e. state motivation) and its relationship with general motivation (i.e. trait motivation). Dörnyei (2002) finds the state/trait dichotomy as too static and suggests a more elaborate conceptualisation of task motivation: it is to be viewed as a complex dynamic result of a number of contextual influences and learner-internal factors that interact with the intrinsic properties of the task. Moreover, its constant variation depends on stages of task engagement, learners' evaluation and monitoring, as well as the effort invested in controlling the task engagement process.

As has been previously noted, this period is also characterised by the attempt to take into consideration contextual influences on motivation. Dörnyei's (1994:280) three-level framework of L2 motivation represents one such attempt. He explains motivation in terms of three main dimensions, i.e. levels. The first is the language level that includes aspects such as culture and the community, as well as pragmatic values and benefits of L2. Next, the learner level encompasses individual characteristics of each learner. These two levels are based on Gardner's and Clément's theoretical perspectives. Finally, the learning situation level targets situation-specific motives connected with classroom settings and may include course-specific motivational components (i.e. the syllabus, the teaching materials, methods and tasks), teacher-specific motivational components (i.e. teacher's influence on learners' motivation), and group-specific motivational components (e.g. goal-orientedness, norm and reward system, classroom goal structure, and group cohesiveness). A change of any parameters at one level may affect overall motivation independently of the other two. For example, learners learning the same language may show different levels of motivation depending on the learning situation. In other words, the learning situation is thought of as being powerful enough to annul the effect of other motives.

By taking a social constructivist approach to motivation, Williams and Burden (1997) were able to bring together the assumption that every individual's motiva- 
tion is different and the assumption that an individual's motivation is influenced by social and contextual factors. The category of learner-internal factors encompasses a host of variables such as intrinsic interest of activity, perceived value of activity, sense of agency, mastery, self-concept, various attitudes, affective states (i.e. confidence and anxiety), developmental age and stage, and gender. The external factors include four dimensions: significant others (parents, teachers, peers), the nature of interaction with significant others, the learning environment (comfort, resources, size of class and school, class and school ethos), and the broader context (wider family networks, the local education system, societal expectations and attitudes, etc.). Their framework of L2 motivation offers a useful classification of factors potentially influencing motivation in the L2 classroom.

The observation that the existing models of L2 motivation failed to incorporate temporal dimension and phases in the motivational process inspired researchers to reconceptualise the construct of motivation. This novel focus gave the third period its name - the process-oriented approach. Williams and Burden (1997) were perhaps the first to argue that motivation is a continuum involving stages from initial arousing interest to sustaining the interest which presupposes investing time, energy and effort. This view was taken up by, among others, Ushioda (1996, 1998), who proposed a theoretical framework of motivation from a temporal perspective in which evolution over time is "central to the learners' experience of and thus conception of language learning motivation" (Ushioda, 1998:82-3). However, the process model of L2 motivation developed by Dörnyei \& Ottó (1998:48) offered a more elaborate description of the L2 motivational fluctuation by focusing on motivation as a dynamic construct constantly changing and influencing learner's success in FLL. Motivation is defined as "the dynamically changing cumulative arousal in a person that initiates, directs, coordinates, amplifies, terminates, and evaluates the cognitive and motor processes whereby initial wishes and desires are selected, prioritized, operationalized, and (successfully or unsuccessfully) acted out" (Dörnyei and Ottó, 1998:64). The model itself has two main dimensions: action sequence and motivational influences. The first dimension represents behavioural process and has three main phases: preactional (made up of three sequential subprocesses: goal setting, intention formation and the initiation of intention enactment), actional (i.e. implementation of the action with three subprocesses: subtask generation and implementation, an ongoing appraisal process, and the application of action control mechanisms or self-regulatory strategies), and postactional phase (or critical retrospection involving evaluating the accomplished action outcome and developing action-specific strategies for future learning). Energy sources and motivational forces are part of the second dimension that fuels the whole process. During the three phases the main motivational influences also change. In the preactional phase, motivation is influenced by goal properties, attitudes and values associated with the learning process, the L2 and its speakers, environmental support or constraints, etc. During the actional phase, the quality of the learning expe- 
rience, sense of autonomy, social influences, use of self-regulatory strategies, etc. are likely to take over. Finally, the main motivational influences in the postactional phase are attributional factors, self-concept beliefs, external feedback and achievement grades.

The value of this model lies in its capacity to describe motivational changes that occur both during a specific learning task and during longer periods of time. However, as one of its authors himself noted, it is not without shortcomings (cf. Dörnyei, 2005; Dörnyei \& Ushioda, 2011). First, it may be impossible to define the onset and offset of actional processes in a real classroom setting, or to demarcate one process from the other. Second, the model cannot take into account multiple goals and agendas that learners may be engaged in. Finally, it fails to overcome the limitations of describing motivation in terms of linear cause-effect relations. In Dörnyei's own words, it simply cannot "do the complexity of the motivation system justice" (2009b:197). This realisation has incited him to embrace the input from a different perspective that seems to offer the necessary radical reformulation and that seems to take into account the complexities of language learning and use in the modern world, namely a complex dynamic systems perspective.

This change of perspective by the leading L2 motivation researcher has helped move the study of L2 motivation into a new theoretical phase which Dörnyei and Ushioda (2011) labelled the socio-dynamic period. A recently published edited volume (Dörnyei et al, 2015), which brings 21 chapters by a number of distinguished applied linguists, bears witness to a growing popularity of adopting dynamic systems theory as the epistemological basis for conceptualizing L2 motivation. Among the new conceptual approaches defining this transition that have had an important bearing on L2 motivational theories are A person-in-context relational view of motivation (Ushioda, 2009), The L2 Motivational Self System (Dörnyei, 2005, 2009a), and Motivation from a complex dynamic systems perspective (Dörnyei, 2009b).

In her person-in-context relational view of motivation Ushioda (2009) focuses on evolving mutual relationship between motivation, self and context. The concept of self encompasses a complex individuality of a person, i.e. his or her various identities (e.g. being a learner, a doctor, Spanish, or being a member of desired 'imagined communities' with particular cultural capital or professional status). She argues that motivation is to be viewed "as an organic process that emerges through this complex system of interrelations" (Ushioda, 2009: 220).

Dörnyei's (cf. 2005, 2009a) L2 Motivational Self System is a motivational theory which unifies psychological theories of the self-system. It is "a motivational framework that seeks to incorporate affective and emotional factors with cognition" (Ryan \& Dörnyei, 2013:91). L2 Motivational Self System suggests that motivation to learn a L2 comes from three different sources: learner's vision of oneself as an effective L2 speaker, the social pressure coming from the learner's environment, and positive learning experiences. Therefore, the system is composed of three elements: the Ideal L2 Self, the Ought-to L2 Self, and the L2 Learning Experience. The 
Ideal L2 Self, one of the fundamental concepts of Dörnyei's theory of L2 learning motivation, is based on learners' hopes, aspirations and goals he/she would like to achieve and it is closely related to Gardner's concept of integrative motivation. It is a powerful motivator to learn L2 because of the learner's desire to reduce discrepancy between his/her actual and ideal self (Dörnyei, 2009a:29). The fully realized Ideal L2 Self is a vivid and real image one can see, hear and feel. A learner can possess a vision as a member of an imagined L2 community partly based on reallife experiences of L2 members, and partly on imagination. Learners are eager to study a L2 in order to achieve their desired "self-image". Therefore, Dörnyei's Ideal L2 Self reflects what Markus \& Nurius (as cited in Dörnyei, 2009a:12) refer to as possible self which involves notions of what individuals would like, might, and are afraid of becoming (Dörnyei, 2009a).

The Ought-to L2 self is a product of learners' obligations, expectations from the social environment, and responsibilities which are expected from her/him in the future as a language learner. This self shares similarities with the instrumental motivation. Also, it refers to characteristics that one should possess in order to be able to control and avoid negative outcomes, obligations and responsibilities. In other words, it keeps learners away from negative consequences of L2 learning (failing exams, disappointing one's parents, getting lower grades etc.). The L2 Learning Experience is derived from the immediate learning environment (teachers, peers, and classroom environment) and learners' perceptions of their previous language learning successes and failures. What this system clearly offers is an opportunity to view learners in relation to who they want to be or become as language users and to consider the multiplicity of underlying motives.

Adoption of a dynamic conception of the notion of motivation has been induced by both the situated and process-oriented conceptualisations of motivation. As Dörnyei \& Ushioda (2011) stress, this approach allows researchers to integrate various aspects of the key factors in SLA, namely the learner, the learning task and the learning environment into a complex system. They argued that L2 motivation in particular lends itself to the analysis from this perspectives because of its inherently changing nature. In line with a complex dynamic systems approach, motivation is a dynamic subsystem entering continuous and complex interactions with other subsystems (i.e. cognition and affect). Thus, instead of isolating discrete motives, researchers should try to identify "higher-order 'motivation conglomerates' that also include cognitive and affective factors and which act as "wholes'" (Dörnyei and Ushioda, 2011:92), such as interest, motivational flow, motivational task processing and future self-guides.

Although there has been little empirical work based on this epistemological view, and although it is still early to know what the future holds for the complex dynamic systems approach and its impact on L2 motivation research and understanding, it shows a lot of promising potential in terms of capturing the complexity 
of L2 motivation and taking into consideration both the context as part of the system and learners as developing individuals.

The above review of different approaches to understanding L2 motivation has shown that motivational construct has been conceptualised in many different ways. However, none of the existing theories of motivation, as Gregersen \& MacIntyre (2014) note, have been wrong. They do not contradict each other: they simply tend to have different focal points. Although the recent approaches taking into consideration variation within and across individuals may provide insight into aspects that remain hidden in traditionally popular large-scale statistical studies, they may not yield all answers either. As Schumann (2015:xvi-xvii) explains, the problem is that "we are dealing with abstract constructs and conceptualizations" and therefore "the number of possible formulations of the phenomena is potentially infinite".

\subsection{Motivation and context}

Regardless of differences in their theoretical focus, all approaches to L2 motivation seem to, in one way or another, take into account context as one of the important elements. Many have acknowledged the idea that human motivation is socially shaped and that the target language community and the social context in general have a great impact on SLA ${ }^{5}$. Learners are necessarily located in specific contexts, they are part of them, and their motivation is shaped by these contexts (cf. Ushioda, 2009, 2015).

However, despite of the explicit acknowledgment of its importance, context has been given limited analysis. The two types of contexts that generated most interest are instructional context (e.g. task and materials design, evaluation practices, grouping structures), and social and cultural influences (e.g. teachers, peer group, school, family, culture and society) (cf. Dörnyei \& Ushioda, 2011). Instructional context may have great influence on learners' short-term motivation, but investigating motivation from a social perspective may also be fruitful. This would include factors such as teachers, peer groups, the whole school ethos, as well as motivational influences exerted by parents and family or even the broader society and culture.

\footnotetext{
${ }^{5}$ Among most influential theories, according to Dörnyei \& Ushioda (2011), are Giles's intergroup model (Giles \& Byrne, 1982, as cited in Dörnyei \& Ushioda, 2011), which focuses on the individual's integration with the other members of the community as well as community itself; Schumann's acculturation theory (1997, as cited in Dörnyei \& Ushioda, 2011), which promotes two concepts - social distance and psychological distance - both seen as crucial factors responsible for individual's SLL/FLL achievement; and Clément \& Noels' (1992) situated language identity approach, which focuses on the individual's maintenance of positive image which results in the motivation of pursuing various linguistic practices.
} 
The parallel existence of many definitions of context may, again, be attributed to different theoretical focal points within the situative perspective on motivation, such as the sociocultural theory, self-regulatory perspectives, and complex dynamic systems approach (Dörnyei \& Ushioda, 2011). Common to these approaches, however, is the view that learners (i.e. their cognitive and affective aspects), context and processes (i.e. behaviours and motivational processes) enter multidirectional dynamic interactions (cf. Dörnyei \& Ushioda, 2011:34). In other words, learners and their motivation are not simply influenced by the context, but learners also shape and define their context. Changes take place both within the learner and within the context (Dörnyei, 2009b). Put differently, context is conceived not in static terms but as a developing process, while the relationship between individuals and context is that of complex and dynamic organic systems emerging and evolving over time. If learners are to be analysed and compared, the environment in which they function must be taken into account.

\subsection{School as context}

Understanding learners motivation in various social units is crucial for formal SLA. Since "for average school students 'school' represents primarily a social arena" (Dörnyei \& Ushioda, 2011:28), it has to be taken into account. As specific social units, schools promote different kinds of ethos, and generally have different climates and policies. Learners and their motivation are subject to these influences. Any contextually-oriented conceptualisation of motivation has to account for the interaction between learners' motivation and the school culture in which they operate (Perry \& Winne, 2004, as cited in Dörnyei \& Ushioda, 2011).

School can be defined as a specific group context with its own group norms, i.e. overt and covert rules and routines which may include explicit school regulations and unofficial norms of learner behaviour, including the so called norm of mediocrity, which refers to the pressure peers may put on each other not to excel (cf. Dörnyei, 2005). Going to a specific school represents a specific type of "actional context" (Dörnyei, 2002:156) which shapes learners motivation in a unique way. Just like Ushioda (2003 as cited in Dörnyei, 2005) observed that the social unit of the classroom affects motivation of an individual learner, which is illustrated by statements such as 'you simply cannot teach in this class' (Dörnyei, 2005:89), a somewhat larger social unit, i.e. school, can, without doubt, have the same, if not greater impact. However, type of school as a variable affecting L2 motivation has not been investigated by many. The present study attempts to fill this void. 


\section{Related research}

Although a number of studies have looked into various features of motivation of EFL learners attending different kinds of schools, few looked into the differences in the type and intensity of motivation between grammar and vocational school learners.

Fehér's (1999) research was conducted in order to investigate factors that motivate Hungarian EFL learners of three types of secondary school: grammar, vocational and trade schools. Based on Dörnyei's motivational framework, the study looked into differences between 373 learners attending a grammar, a vocational and a trade secondary school. In general, regardless of the type of school, results showed that motivation is positive and has an important role in learning English. All variables, except for language anxiety and linguistic self-confidence, showed almost maximum values. As for the differences among various types of school, the results indicated significant differences in instrumental motivation, i.e. the perceived pragmatic benefits of English proficiency. Grammar school learners were significantly more instrumentally motivated than participants from the other two schools. Fehér assumed that grammar school learners attached more importance to English proficiency for their future career because they were either more aware of the importance of speaking foreign languages in general, or were more likely to look for jobs where knowledge of English would be a requirement. Moreover, grammar school learners had significantly higher interest in English culture than learners from vocational and trade schools, which Fehér attributes to the differences in both overall curricula and specific EFL syllabi. On the whole, findings showed that motivation plays an important role in EFL learning regardless of the type of secondary school.

Another study carried out in the Hungarian EFL learning context based on Dörnyei's motivational framework also took into account the type of secondary school as a variable influencing motivation. Csizér \& Kormos (2008) reanalysed data obtained from a host of studies (including the one by Fehér) which were conducted over the span of seven years and which included over 700 learners attending grammar, vocational and trade secondary schools. The results indicated overall high levels of motivation across the secondary school population. School type affected different components of L2 motivation. The least favourable motivational characteristics were found in trade school learners, whereas grammar school and vocational school learners differed only in some aspects. In particular, grammar school learners manifested more favourable attitudes towards English cultural products and found the instrumental values of speaking English more important than learners from the two other types of school. They also had more positive attitudes toward language classes than vocational school learners. Vocational school learners displayed a significantly higher level of willingness to invest effort into learning English than trade school learners. The regression models for the three 
types of school showed that only the model for grammar school learners included instrumental values, which were replaced by cultural orientation in the other two models. In addition, only the model for trade school learners included selfconfidence and anxiety, which implies that individual differences in these two personality factors significantly affect trade school learners' L2 motivation.

Sarani \& Ahmadi (2013) examined two aspects of EFL in Iran: motivation toward EFL learning, as measured by AMTB, and levels of language proficiency, measured by means of a beginner English Proficiency Test. With regard to motivation, special attention was paid to the differences between male and female vocational school learners. The study involved 57 male and 50 female learners from a vocational and 53 male learners from a grammar secondary school. Their research revealed that male grammar school learners have higher EFL proficiency level than those in vocational school. Secondly, male learners attending grammar school were more motivated than those of vocational school. Thirdly, as regards differences between male and female learners attending vocational school, female learners were more motivated than the male. All in all, it is important to stress that the knowledge of English in Iran is seen an essential requirement for military service and different job opportunities for young people which can also serve as a certain explanation for the presented results.

\section{Comparison of Vocational and Grammar School learners' moti- vation in EFL}

In Croatian socio-educational context, research on learners' EFL motivation with particular focus on the relationship between motivational types and intensity and secondary school type has, to the best of our knowledge, not been conducted. The present study sets out to fill that void.

By focusing on groups of learners, the present study intends to examine the commonalities in their attributes, i.e. their thoughts and emotional stances at a particular point in time and in a particular context. Since there is currently no single theoretical approach that could fully inform a situative approach to investigating L2 motivation, we attempt to take a multidimensional theoretical approach. Starting from the motivational framework suggested by Mihaljević Djigunović (1998), this study attempts to expand the underlying theoretical perspective by focusing on situation-specific variable, i.e. context defined by the type of school. Thus, by carrying out a more situated analysis of the characteristics and motivational patterns of learners operating in two types of schools, we attempt to find a balance between the macro and microperspective in the hope that a more complex picture of L2 motivation will arise, as put forward by advocates of the cognitivesituated view of motivation. Taking into account the type of school learners attend is in line with the assumption that it represents (one of many) learners' immediate 
learning environments which has its own motives that can "play a facilitative, neutral, or inhibitory role with respect to further learning" (McGroarty, 2001:86).

\subsection{Defining the context}

The context in which participants in this study are situated is the type of secondary school in the Croatian socio-educational setting. There are two types of secondary schools in Croatia: vocational and grammar schools. Both can be enrolled after completing eight years of primary education. Within vocational schools, two types of programmes are offered: a four-year programme (i.e. vocational schools), and a three-year programme (i.e. trade schools). Whereas grammar schools provide learners with general education by offering a balanced ratio of science, humanities and languages, vocational and trade schools focus on giving learners training in a particular profession. As for EFL, it is a mandatory school subject in all four years of grammar schools, and majority of vocational and trade schools. Grammar schools typically have 3 or 4 class periods a week (i.e. 105 or 140 classes annually), whereas vocational schools have 2 or 3 weekly classes (i.e. 70 or 105 classes a year), depending on the school. However, some vocational schools apply the EFL syllabus designed for grammar schools. Learners who enrol in vocational and trade schools usually have lower GPA and lower levels of prior knowledge of English. To conclude, grammar schools are more and vocational/trade schools less homogenous in terms of the EFL status in the curriculum, EFL syllabi, and learners' proficiency. Finally, there can be a great gender imbalance in secondary schools, so that some schools appear to be single-gender schools.

Learners of English in Croatia have little direct contact with English native speakers but considerable contact with non-native speakers of English. Moreover, there is considerable contact with English and the culture of various Englishspeaking communities through the media. In fact, the context of learning English in Croatia displays many features of an L2 learning context in terms of the amount and quality of input readily available outside classroom. (cf. Pavičić Takač \& Bagarić, 2011).

\subsection{Aims}

The aim of this study is to determine and compare types and intensity of motivation of learners attending two types of secondary schools: grammar and vocational schools. The motivational dimensions investigated in the present study are based on Mihaljević Djigunović's (1996; 1997; 1998) motivational framework (see Section 2) and include pragmatic-communicative, integrative and affective motivation types, as well as two demotivators, the teaching setting and learning difficulties. There are two additional variables included in the analysis: gender and English proficiency. As has already been explained, due to a great gender imbalance in 
secondary schools, gender has to be taken into account as a potentially important variable that may influence the affect of school type. Learners' course grade is taken as an indicator of English proficiency. In Croatian educational system, grades range from 1 to 5, with 5 being the highest, 2 the lowest passing grade, and 1 the failing grade.

The present study seeks to answer the following questions:

a) What is the relationship among type of school, gender, and EFL proficiency on pragmatic-communicative motivation between participants?

b) What is the relationship among type of school, gender, and EFL proficiency on affective motivation between participants?

c) What is the relationship among type of school, gender, and EFL proficiency on integrative motivation between participants?

d) What is the relationship among type of school, gender, and EFL proficiency on the teaching setting demotivator between participants?

e) What is the relationship among type of school, gender, and EFL proficiency on the learning difficulties demotivator between participants?

\subsection{Sample}

A total of 541 students from secondary schools in Osijek, Croatia participated in this study: 207 four-year vocational school learners (The Agricultural and Veterinary School, The Catering and Tourism School, and The Building and Geodetic School) and 334 learners attending three grammar schools and The Art and Design School. The Art and Design School follows the EFL programme designed for grammar schools, and was therefore, together with the three grammar schools, categorized as a grammar school in the data analysis. All participants were Croatian, aged between 15 and $19(\mathrm{M}=16.91 ; \mathrm{SD}=.678)$, and have English as an obligatory school course. Their average English grade is $3.68(\mathrm{SD}=1.058)$. More specifically, grammar school learners' average grade is $3.77(\mathrm{SD}=1.003)$ and vocational school learners' average grade was $3.53(\mathrm{SD}=1.127)$. This difference was found to be significant $\left(\mathrm{t}_{(539)}=2.558 ; \mathrm{p}<.011\right)$.

\subsection{Instruments and Procedure}

To assess the probability of observing patterns of relationships and group differences in motivational types and intensity of Croatian EFL learners Mihaljević Djigunović's (1998) Types and Intensity of Motivation for learning EFL Questionnaire was used. This particular questionnaire was selected for two reasons. First, since motivation questionnaires are highly context-dependent, it seems most suitable to use a questionnaire validated in participants' L1 and adapted to the target learning context. Secondly, it also includes demotivation as an important aspect of motivation. Defined as "specific external forces that reduce or diminish the motivational 
basis of a behavioural intention or an ongoing action" (Dörnyei \& Ushioda, 2011:139), demotivation can be highly context-dependent.

With its 38 items, the Types and Intensity of Motivation for learning EFL Questionnaire covers five motivational dimensions: pragmatic-communicative, affective, and integrative motivation, and the teaching setting and learning difficulties demotivators. The statements are followed by a five-point Likert scale: (1) strongly disagree, (2) slightly disagree, (3) neither agree nor disagree, (4) slightly agree, (5) strongly agree. The questionnaire was distributed in Croatian, i.e. participants' L1. It was administered during regular English classes. Participants were informed about the purpose of the study and that their participation was anonymous and voluntary. It took them on average 15 minutes to complete the questionnaire.

Cronbach's alpha for internal reliability of the questionnaire in this study was .79 , which indicates highly focused scales and homogeneity.

To answer the research questions, a $(2 \times 2 \times 2)$ three-way analysis of variance (ANOVA) was conducted which included type of school (grammar/vocational), gender (male/female) and EFL course grade [low-grade $(1,2,3)$ and high-grade (4, $5)$ ] as independent, and types of motivation as dependent variables. Significance level was set at $p<0.05$. Separate analyses of variance were conducted for each component of motivation. The statistical analysis was performed using SPSS (Version 19).

\subsection{Results and discussion}

Results of the descriptive statistics regarding the intensity of each type of motivation for learning EFL for the whole sample (see Table 1) indicate that the strongest motivational dimension of Croatian EFL learners is pragmatic-communicative, which is followed by affective motivation and one of the demotivators, namely the teaching setting. Integrative motivation and the learning difficulties demotivator seem to be less pronounced in this sample. These findings are in line with previous research: Croatian learners are characterised by pragmatic-communicative type of motivation rather than integrative (cf. Mihaljević Djigunović, 1998).

Table 1: Scores on Types and Intensity of Motivation for Learning EFL Questionnaire $(N=541)$

\begin{tabular}{cccccc}
\hline & $\begin{array}{c}\text { Pragmatic- } \\
\text { communicative } \\
\text { motivation }\end{array}$ & $\begin{array}{c}\text { Affective } \\
\text { motivation }\end{array}$ & $\begin{array}{c}\text { Integrative } \\
\text { motivation }\end{array}$ & $\begin{array}{c}\text { The teach- } \\
\text { ing setting } \\
\text { demotiva- } \\
\text { tor }\end{array}$ & $\begin{array}{c}\text { The learning } \\
\text { difficulties de- } \\
\text { motivator }\end{array}$ \\
\hline Mean & $\mathbf{4 . 1 6}$ & 4.06 & 2.93 & 2.55 & 1.98 \\
SD & .71 & .97 & 1.12 & 1.04 & .82 \\
\hline
\end{tabular}




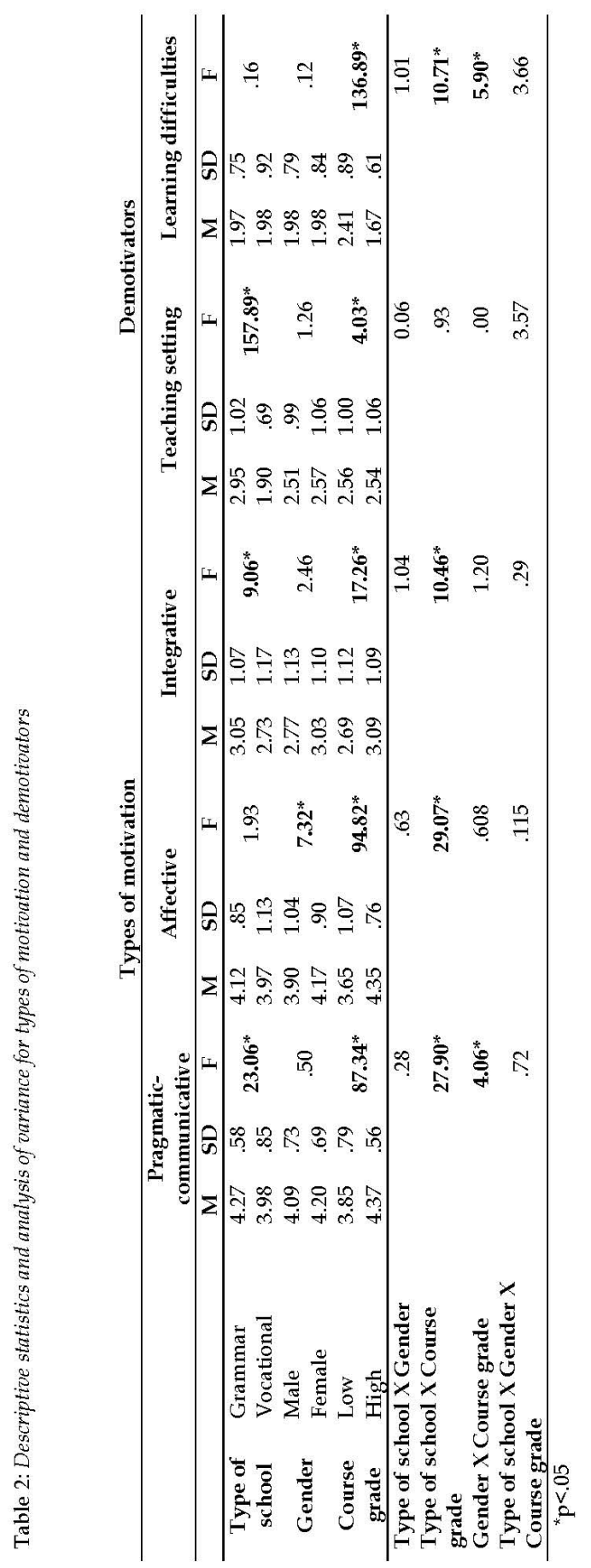


The results presented in Table 2 show the descriptive statistics and analysis of variance for the three types of motivation and two demotivators. The results indicate that grammar school learners rate themselves significantly lower than vocational school learners on the pragmatic-communicative motivation. Also, participants with higher course grades have statistically significantly higher pragmaticcommunicative motivation than participants with low course grades.

As can be seen in Table 2, interactions between type of school and gender and type of school, gender and grade are not statistically significant. On the other hand, interactions between type of school and grade and gender and grade appear statistically significant (see Figure 1). Analysis of type of school shows that pragmatic-communicative motivation is statistically significantly higher among participants with high course mark in both types of school, but the difference is greater among vocational school learners.

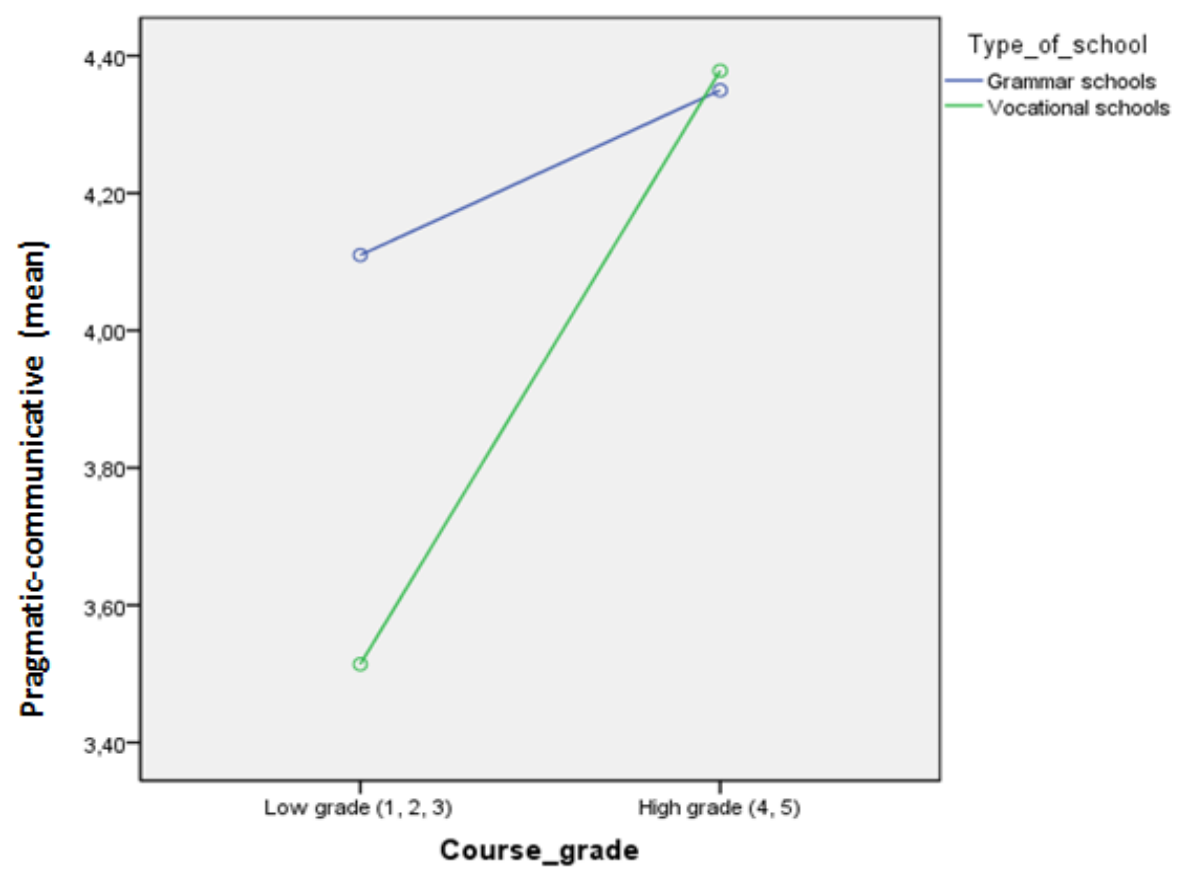

Figure 1: Grade and Type of School Interaction

Gender analysis (Figure 2) indicates that in both female and male learners, the higher pragmatic-communicative motivation, the higher the course grades. However, the effect is greater in female learners. 


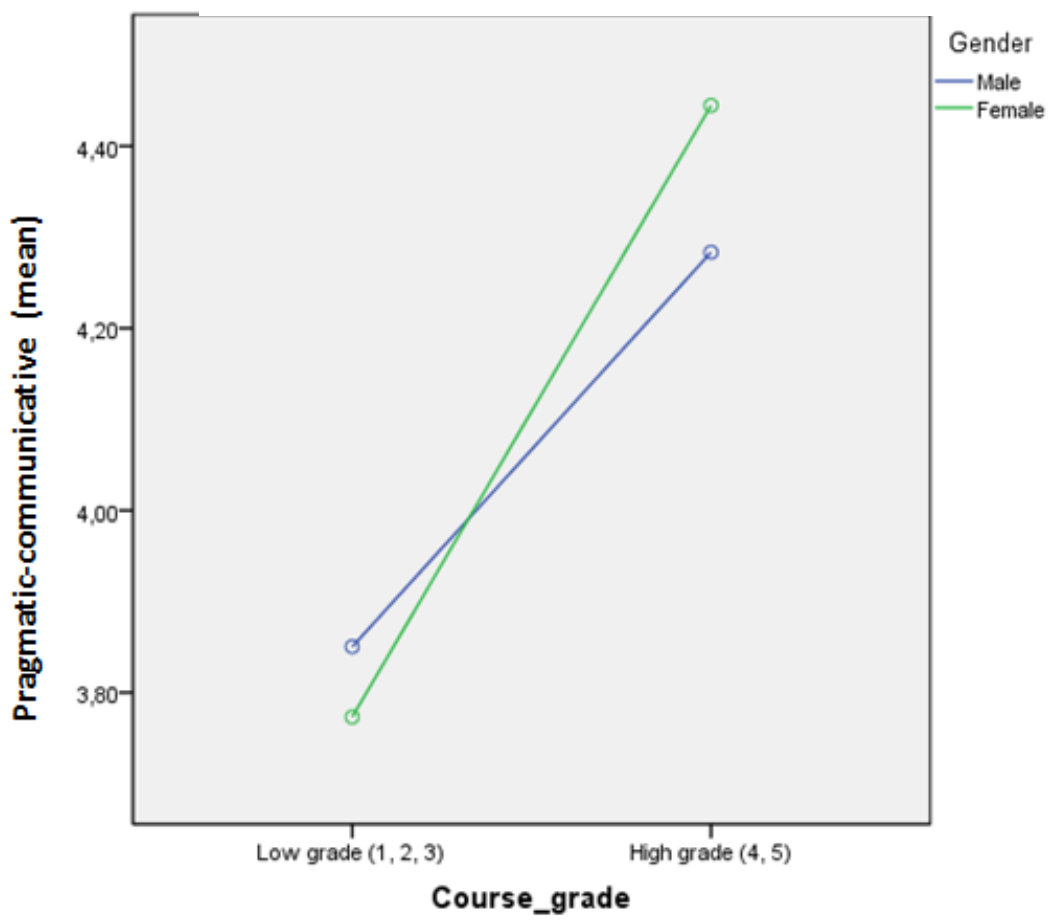

Figure 2: Course grade and Gender Interaction

As for the first research question concerning the pragmatic-communicative motivation, results show that learners attending grammar schools are more motivated than those attending vocational schools. High motivation is particularly evident among learners with high grades regardless of the type of school they attend. These findings are compatible with Mihaljević Djigunovićs study (1998) where better learners were found to be more motivated than weak learners. High pragmaticcommunicative motivation among grammar learners might be explained by the EFL teaching curriculum. Grammar school learners are exposed to a wide range of information about cultural issues and customs of English speaking communities which then increases their desire to learn the language. They perceive English as a language of international communication from which they can benefit in the future (e.g. if they wish to study at a foreign university, or find a job). On the other hand, vocational school learners are exposed to English restricted to specific purpose connected to their future professions which may narrow their view of English as a great communicative tool in the globalized world.

As for affective motivation, mean values presented in Table 2 show a significant difference between female and male participants, with higher affective moti- 
vation associated with female participants. The results are compatible with Mihaljević Djigunović's (1998) study which showed that female learners are more emotionally connected to FL than male learners. A possible explanation might lie in the fact that female learners may more readily acknowledge their feelings which is in line with conventional beliefs that females are more emotionally expressive than males (Parkins, 2012). Moreover, participants with high course grades demonstrate higher affective motivation than participants with low grades.

Analysis of variance shows that only the interaction between type of school and course grade is statistically significant. Figure 3 shows that both grammar and vocational school learners with high grades display high levels of affective motivation, but the effect is greater in vocational school learners. There is also a significant difference in affective motivation intensity between vocational school learners with low grades and those of grammar schools with the same grades, with the latter demonstrating higher intensity of this type of motivation.

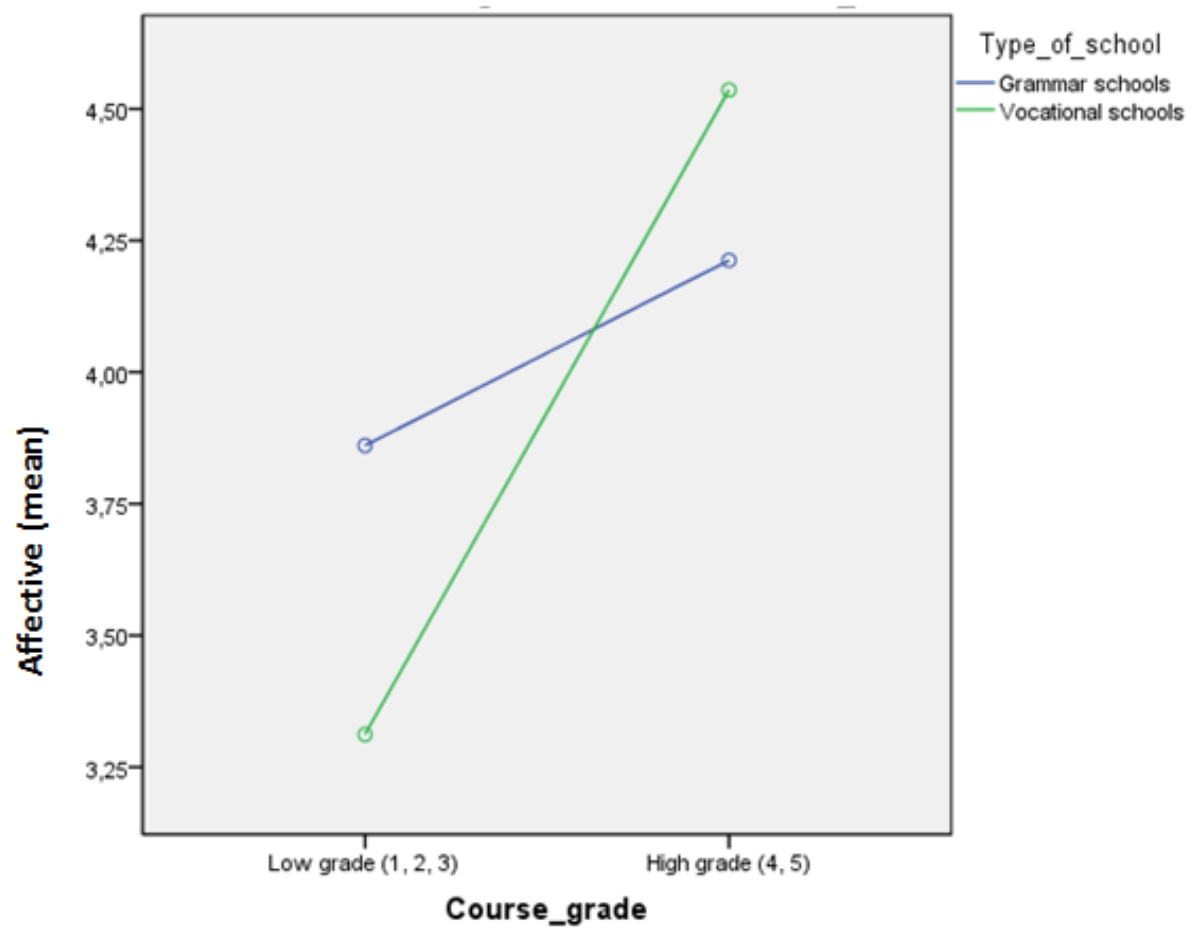

Figure 3: Grade and Type of School Interaction

As can be seen in Table 2, there is a statistically significant difference in integrative motivation between grammar and vocational school learners. It also appears 
that more proficient participants are more integratively motivated than less proficient participants.

Analysis of variance shows that interaction between type of school and grade is statistically significant. A slight increase in course grades is associated with the rise in integrative motivation. This effect is greater among vocational school learners (Figure 4).

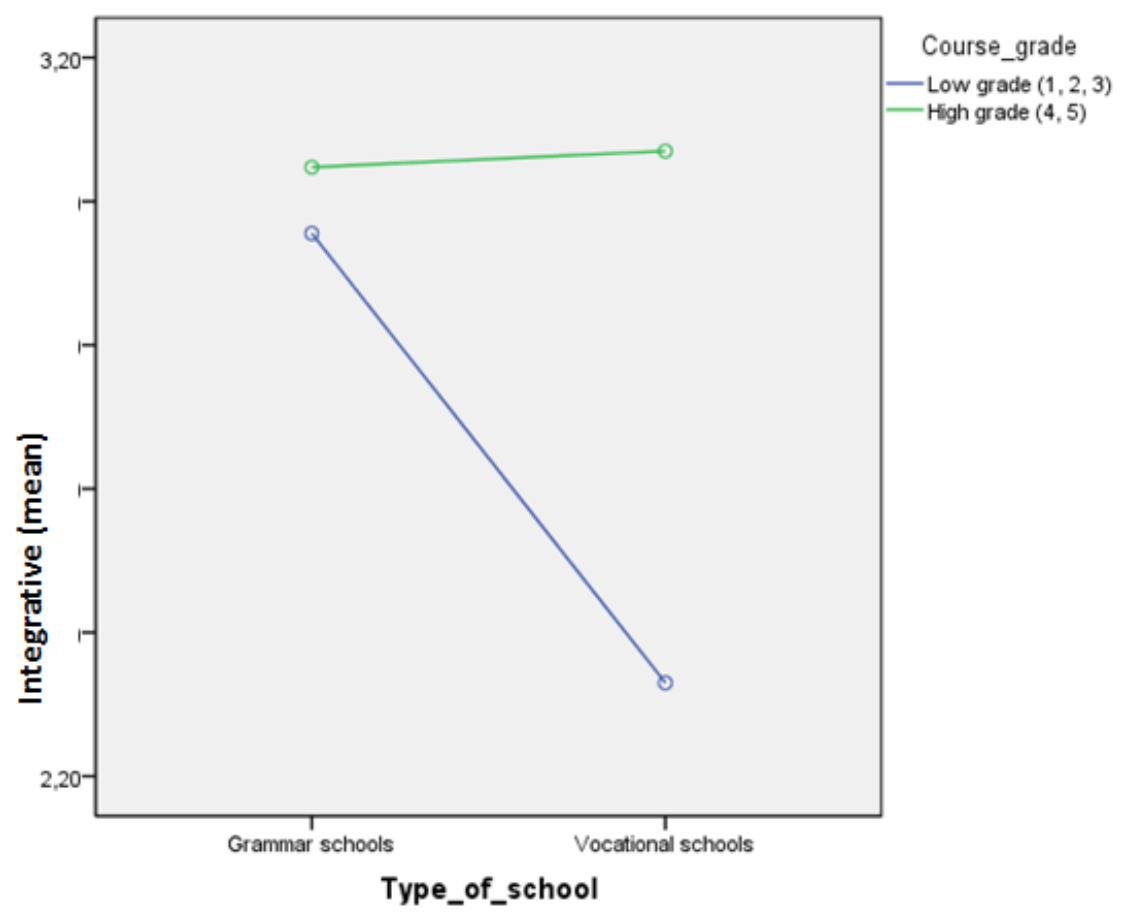

Figure 4: Grade and type of school interaction

Table 2 shows that there is a significant difference in mean values for the teaching setting demotivator between grammar and vocational school learners. Also, less proficient participants more often find the teaching setting demotivating than more proficient learners.

There are no significant interactions between variables.

Regarding the third research question, the mean values show that learners of grammar schools are more motivated than those of vocational schools. The results seem to corroborate Gardner's (1985) findings that the need for integration in the other community is present to a great extent. The only difference is that in the Croatian social-educational context learners do not have many opportunities to communicate with native speakers of English. The level of their integrative motivation 
may depend mainly on the teacher, materials and the classroom setting. Furthermore, the reason for vocational school learners' low integrative motivation can lie in the fact that they are not exposed to the teaching materials featuring native speakers of English to the same extent as their peers of grammar schools.

The results concerning the fourth research question show that grammar learners more often tend to consider the teaching setting as a demotivator compared to their peers from vocational schools. It appears that grammar learners find the teachers' choice of materials, its implementation in the classroom context as well as the classroom atmosphere insufficient for their progress in EFL learning. According to Mihaljević Djigunović (1998), those learners will look for other ways to improve their English language (language schools, private lessons, etc.), and finally form a negative attitude toward the teaching setting itself. On the contrary, vocational learners seem satisfied with the information provided in the classroom and find it beneficial for their future professions. It also appears that less successful learners often tend to find the teaching setting demotivating. The results of this study can be compared to Sakai and Kikuchi's (2009) study where two main demotivators (learning contents and teaching material, and test scores) for less motivated students were identified.

Results in Table 2 show that learners with high grades have fewer difficulties in learning EFL than participants with low grades.

Interactions between type of school and grade and gender and grade appear statistically significant. Figure 5 shows that learning difficulties demotivator is more manifest in vocational school learners with low grades than grammar school learners with the same grades. On the other hand, it is more pronounced in grammar school learners with high grades than in their peers from vocational schools with high grades. Interaction appears as a result of a more prominent presence of learning difficulties demotivator in grammar school learners with high grades than in vocational school learners with high grades.

The results concerning the fifth research question on the learning difficulties demotivator show that learners of both types of school with high grades have fewer learning difficulties compared to those with low grades (see Figure 6). The findings are compatible with Mihaljević Djigunović's (1998) study where less successful learners experience more learning difficulties because of the lack of basic knowledge. It is important to note that, when it comes to being demotivated, Dörnyei (2005:90) argued that it "does not necessarily mean that all the positive influences that originally made up the motivational basis of a behaviour have been annulled; rather, it is only the resultant force that has been dampened by a strong negative component". Detecting the real source of demotivation calls for a more individualised approach in both research and practice. 


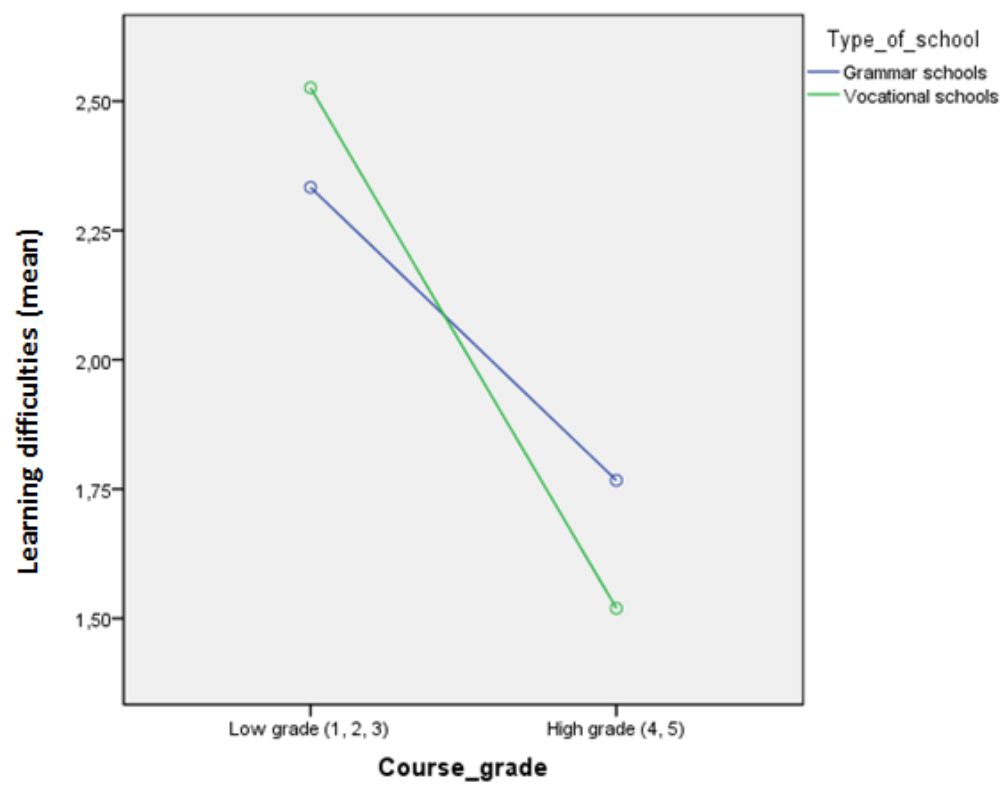

Figure 5: Grade and type of school interaction

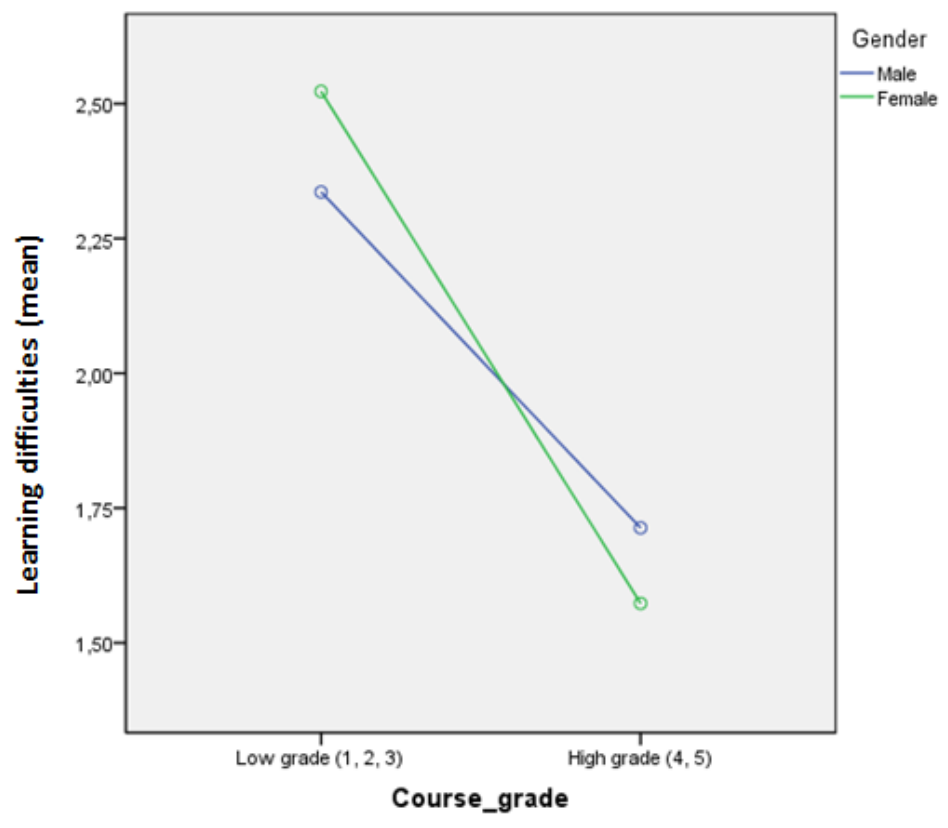

Figure 6: Grade and gender interaction 


\section{Conclusion}

Language learning is a complex processes influenced by a number of cognitive and affective factors. This paper explored motivation as one of the most important affective factors in language learning. The primary focus was on comparing vocational and grammar school learners' EFL motivation in Croatian socio-educational context. In particular, we investigated the relationship among type of school (i.e. vocational and grammar school), gender, and EFL proficiency (measured by course grades) on three components of motivation (pragmatic-communicative, affective and integrative) and two demotivators (the teaching setting and learning difficulties).

The results showed that the most representative type of motivation is pragmatic-communicative, which is followed by affective motivation. Moreover, the most representative demotivator is the teaching setting. Furthermore, integrative motivation and the learning difficulties demotivator appear less important. The analysis of variance showed that the type of school learners attend and their learning success may play a significant role in EFL learning.

There are more than a few limitations of this study. Although we are aware that the linear approach we opted for does not capture the full complexity of learners' L2 motivation, we believe that a study like the present one offers a valuable snapshot of the role of context in L2 motivation. The present findings may serve as a springboard for future research which should seek to incorporate the dynamic aspect of the interaction between motivation and context. Although the complete answer to the question of why people do what they do may always remain elusive words, as Dörnyei (2005) said, research on L2 motivation goes on.

\section{References}

Arnold, Jane (2011). Attention to affect in language learning. Anglistik: International Journal of English Studies 22, 11: 11-22.

Clément, Richard, Susan C. Baker, \& Peter D. MacIntyre (2003). Willingness to communicate in a second language: The effects of context, norms and vitality. Journal of Language and Social Psychology 22: 190-209.

Clément, Richard, \& Kimberly A. Noels (1992). Towards a situated approach to ethnolinguistic identity: The effects of status on individuals and groups. Journal of Language and Social Psychology 11: 203-32.

Clément, Richard, Kimberly A. Noels, \& Bernard Denault (2001). Interethnic contact, identity, and psychological adjustment: the mediating and moderating roles of communication. Journal of Social Issues 57: 559-77.

Cohen, Andrew D., \& Zoltán Dörnyei (2002). Focus on the language learning: Motivation, styles, and strategies. Schmitt, Norbert, ed. An Introduction to Applied Linguistics. London: Arnold, 170- 190. 
Crookes, Graham, \& Richard W. Schmidt (1991). Motivation: Reopening the research agenda. Language Learning 41: 469-512.

Csizer, Kata, \& Judit Kormos (2008). An overview of Hungarian secondary school students' foreign language motivation. Hans Knudsen, ed. Secondary Education Issues and Challenges. New York: Nova Science Publishers, 59-84.

Deci, Edward L., \& Richard M. Ryan (1985). Intrinsic Motivation and Self-Determination in Human Behavior. New York: Plenum Press.

Dörnyei, Zoltán (1990). Conceptualizing motivation in foreign language learning. Language Learning, 40, 1: 45-78.

Dörnyei, Zoltán (1994). Motivation and motivating in the foreign language classroom. Modern Language Journal 78: 273-84.

Dörnyei, Zoltán (1998). Motivation in Second and Foreign Language Learning. Language Teaching 31: 117-135.

Dörnyei, Zoltán (2001a). Teaching and Researching Motivation. Harlow: Longman.

Dörnyei, Zoltán (2001b). New themes and approaches in second language motivation research. Annual Review of Applied Linguistics 21: 43-59.

Dörnyei, Zoltán (2002). The motivational basis of language learning tasks. Robinson, Peter, ed. Individual Differences and Instructed Language Learning. Amsterdam: John Benjamins: $137-58$.

Dörnyei, Zoltán (2005). The Psychology of the Language Learner: Individual Differences in Second Language Acquisition. Mahwah, NJ: Lawrence Erlbaum.

Dornyei, Zoltán (2009a). The L2 Motivational Self System. Dornyei, Zoltán, Ema Ushioda, eds. Motivation, Language Identity and the L2 Self. Bristol: Multilingual Matters, 9-42.

Dörnyei, Zoltán (2009b). Individual differences: interplay of learner characteristics and learning environment. Ellis, Nick C., Diane Larsen-Freeman, eds. Language as a Complex Adaptive System. Oxford: Wiley Blackwell, 230-248.

Dörnyei, Zoltán, \& István Ottó (1998). Motivation in action: A process model of L2 motivation. Working Papers in Applied Linguistics 4: 43-69.

Dörnyei, Zoltán, \& Peter Skehan (2003). Individual differences in second language learning. In: Catherine J. Doughty, Michael H. Long, eds. The Handbook of Second Language Acquisition. Oxford: Blackwell, 589-630.

Dornyei, Zoltán, \& Ema Ushioda (2011). Teaching and Researching Motivation. Harlow etc: Pearson.

Dörnyei, Zoltán, Peter MacIntyre, Alastair Henry (eds.) (2015). Motivational Dynamics in Language Learning. Bristol, Buffalo, Toronto: Multilingual Matters.

Ehrman, Madeline, Betty Lou Leaver, Rebecca Oxford (2003). A brief overview of individual differences in second language learning, System, 31, 3: 313-330.

Fehér, Endre (1999). Motivation in Learning English at Three Secondary Schools in Újpest. Szombathely/Budapest: Berzsenyi Dániel Teacher Training College [unpublished M.A. dissertation].

Gardner, Robert C. (1985). Social Psychology and Language Learning: the Role of Attitudes and Motivation. London: Edward Arnold.

Gardner, Robert C. (2001). Integrative motivation and second language acquisition. Dörnyei, Zoltán, Richard Schmidt, eds. Motivation and Second Language Acquisition. Honolulu: University of Hawaii, 1-19.

Gardner, Robert C. (2007). Motivation and Second Language Acquisition, Porta Linguarium 8: 9-20. 
Gardner, Robert C., \& Wallace E. Lambert (1972). Attitudes and Motivation in Second Language Learning. Newbury House: Rowley.

Gardner, Robert C., \& Peter D. MacIntyre (1993). A student's contribution to second language learning. Part II: Affective variables, Language Teaching 26: 1-11.

Gregersen, Tammy, \& Peter MacItyre (eds.) (2014). Capitalizing on Language Learners' Individuality: From Premise to Practice. Bristol, Buffalo, Toronto: Multilingual Matters.

Julkunen, Kyosti (1989). Situation and Task-Specific Motivation in Foreign-Language Learning and Teaching. Joensuu: University of Joensuu.

Julkunen, Kyosti (2001). Situation- and task-specific motivation in foreign language learning. Dörnyei, Zoltán, Richard Schmidt, eds. Motivation and Second Language Acquisition. Honolulu: University of Hawaii Press, 29-41.

Lambert, Wallace E. (1972). Language, Psychology, and Culture: Essays by Wallace E. Lambert. Stanford: Stanford University Press.

MacIntyre, Peter D. (2002). Motivation, anxiety and emotion in second language acquisition. Robinson, Peter, ed., Individual Differences in Second Language Acquisition. Amsterdam: John Benjamins, 45-68.

McGroarty, Mary (2001). Situating second language motivation. Dörnyei, Zoltán, Richard Schmidt, eds. Motivation and Second Language Acquisition. Honolulu, H: University of Hawaii Press, 69-90.

Mihaljević Djigunović, Jelena (1996). Learner motivation as a source of variance in attitudes, effort and achievement. Studia Romanica et Anglica Zagrabiensia 41: 211-223.

Mihaljević Djigunović, Jelena (1997). Research on the affective domain in EFL learning: a study of motivation. Studia Romanica et Anglica Zagrabiensia 42: 257-268.

Mihaljević Djigunović, Jelena (1998). Uloga afektionih faktora u učenju drugoga jezika [Role of Affective Factors in FLL]. Zagreb: Filozofski fakultet Sveučilišta u Zagrebu.

Noels, Kimberly A. (2009). The internalisation of language learning into the self and social identity. Dörnyei, Zoltán, Ema Ushioda, eds. Motivation, Language Identity and the L2 Self. Bristol: Multilingual Matters, 295-313.

Noels, Kimberly A., Richard Clément, \& Luc G. Pelletier (1999). Perceptions of teachers' communicative style and students' intrinsic and extrinsic motivation. Modern Language Journal 83: 23-34.

Noels, Kimberly A., Richard Clément, \& Luc G. Pelletier (2001). Intrinsic, extrinsic, and integrative orientations of French Canadian learners of English. Canadian Modern Language Review 57: 424- 44.

Noels, Kimberly A., Luc G. Pelletier, Richard Clément, \& Robert J. Vallerand (2000). Why are you learning a second language? Motivational orientations and selfdetermination theory. Language Learning 50: 57-85.

Oxford, Rebecca, \& Jill Shearin (1994). Language learning motivation: Expanding the theoretical framework. The Modern Language Journal 78, 1: 12-28.

Parkins, Róisín (2012). Gender and Emotional Expressiveness: An Analysis of Prosodic Features in Emotional Expression. Griffith Working Papers in Pragmatics and Intercultural Communication 5, 1: 46-54.

Pavičić Takač, Višnja, \& Vesna Bagarić (2011). Foreign Language Acquisition in space and time: A comparative analysis of the Croatian foreign language acquisition context. Brdar, Mario et al., eds. Space and Time in Language. Frankfurt itd: Peter Lang, 329351. 
Pintrich, Paul R. (2003). Motivation and classroom learning. Reynolds, William M., Gloria E. Miller, eds. Handbook of Psychology. New Jersey: John Wiley \& Sons, 103-122.

Reid, Joy (1999). Affect in the classroom: problems, politics and pragmatics. Arnold, Jane, ed. Affect in Language Learning. Cambridge University Press, 297-306.

Robinson, Peter (ed.) (2002). Individual Differences and Instructed Language Learning. Amsterdam: John Benjamins.

Ryan, Stephen, \& Zoltán Dörnyei (2013). The long-term evolution of language motivationand the L2 self. Berndt, Annette, ed. Fremdsprachen in der Perspektive lebenslangen Lernens. Frankfurt: Peter Lang, 89-100.

Sarani, Abdullah, \& Mehdi Ahmadi (2013). A study of vocational and non-vocational high school learners' language proficiency and motivation. Advances in Asian Social Science 4, 3: 892-898.

Sakai, Hideki, \& Keita Kikuchi (2009). An analysis of demotivators in the EFL classroom. System 37, 1: 57-69.

Schumann, John H. (2015). Foreword. Dörnyei, Zoltán, Peter MacIntyre, Alastair Henry, eds. Motivational Dynamics in Language Learning. Bristol, Buffalo, Toronto: Multilingual Matters, xv-xix.

Ushioda, Ema (1996). Developing a dynamic concept of L2 motivation. Hickey, Tina, Jenny Williams, eds. Language, Education and Society in a Changing World. Dublin/Clevedon: IRAAL/Multilingual Matters: 239- 45.

Ushioda, Ema (1998). Effective motivational thinking: A cognitive theoretical approach to the study of language learning motivation. Soler, Eva Alcón, Victoria Codina Espurz, eds. Current Issues in English Language Methodology. Castelló de la Plana: Universitat Jaume I: 77-89.

Ushioda, Ema (2009). A person-in-context relational view of emergent motivation, self and identity. Dörnyei, Zoltán, Ema Ushioda, eds. Motivation, Language Identity and the L2 Self. Bristol: Multilingual Matters: 215-28.

Ushioda, Ema (2015). Context and complex dynamic systems theory. Dörnyei, Zoltán, Peter MacIntyre, Alastair Henry, eds. Motivational Dynamics in Language Learning. Bristol, Buffalo, Toronto: Multilingual Matters. 47-54.

Williams, Marion, \& Robert Burden (1997). Psychology for Language Teachers. Cambridge: Cambridge University Press.

Received September 7, 2015

Accepted for publication September 15, 2015

Authors' address:

Filozofski fakultet

Jägerova 9,

31000 Osijek

e-mail: vpavicic@ffos.hr 